Revista Ibero-Americana de Ciências Ambientais

Ibero-American Journal of Environmental Science

Anais do Simpósio Interdisciplinar de Práticas de Produção

Agrícola e Conservação Ambiental - Jan 2017 - v.8 - n.1

\title{
Aspectos socioeconômico dos agricultores familiares extrativistas do cumbaru no município de Poconé - Pantanal Mato-Grossense
}

\begin{abstract}
O Dipteryx alata Vogel (cumbaru) é uma espécie arbórea de importância econômica, em virtude dos atributos do seu fruto como alimento humano e animal. Atraiu atenção nos círculos de discussão da conservação como alternativa de exploração sustentável e composição das cadeias produtivas da biodiversidade. É de importância econômico-social para a comunidade pesquisada, pois apresenta uma alternativa de ocupação e renda para agricultores familiares rurais. Intentou-se traçar o perfil socioeconômico dos agricultores familiares que desenvolvem atividade extrativista do fruto de cumbaru no município de Poconé-MT. Os dados foram obtidos a partir de entrevistas, com formulário semiestruturado, a vinte e dois agricultores, selecionados por amostragem não probabilística, pela técnica "snowball", no primeiro semestre de 2014. Constatou-se que o agente extrativista é representado por comunidades tradicionais, descendentes de índios e quilombolas, destarte pequenos agricultores rurais. A atividade extrativista é predominantemente feminina, cuja idade varia entre 29 e 68 anos, e o percentual de analfabetismo é de $31 \%$. 0 extrativismo do fruto do cumbaru está presente entre as três principais fontes de renda para $82 \%$ das famílias e contribui para pagamento das despesas básicas, como vestuário e alimentação. A atividade extrativista no meio rural de Poconé contribui para a permanência dos agricultores na terra, demonstrando princípios de desenvolvimento econômico, social e ambiental.
\end{abstract}

Palavras-chave: Atividade Não-Agrícola; Desenvolvimento Rural; Sustentabilidade.

\section{Socioeconomic aspect of family agriculturists extractives of the cumbaru fruit in the town of Poconé, Pantanal of Mato Grosso}

\begin{abstract}
The Dipteryx alata Vogel (cumbaru) is an arboreal specie, of economic importance due to the attributes of its fruit as human and animal food. It has gained attention in conservation discussion circles as an alternative for sustainable exploration and in the composition of biodiversity production chains. It has economic-social importance to the researched community, because it provides an alternative for occupation and income to family rural agriculturists. It was intended to trace the socioeconomic profile of family agriculturists that develop extractive activity of the fruit of cumbaru in the town of Pocone in Mato Grosso. Data were collected through interviews using a semi-structured questionnaire answered by twenty-two agriculturists, selected by the non-probability sampling, by the"snowball" technique, in the first semester of 2014 . It was found that the extractive agent is represented by traditional communities descendants of Indians and Quilombolas, thus small rural farmers. The extractives are predominantly made by women, which ages may vary between 29 to 68 years old and illiteracy percentage is of $31 \%$. The extractive of the fruit of cumbaru is among the three main income sources of $82 \%$ of the households and contributes to the payment of the main expenses, such as clothing and food. The extractive activity in the rural areas of Pocone contributes to the permanence of the farmers in the lands, showing economic, social and environment development.
\end{abstract}

Keywords: Non-agricultural Activity; Rural Development; Sustainability.

Topic: Química Agrícola e Ambiental

Reviewed anonymously in the process of blind peer.

Sonia Aparecida Beato Ximenes de Melo Universidade do Estado de Mato Grosso, Brasil http://lattes.cnpq.br/3161014550783130 msc.soniaximenes@gmail.com

Fabrício Schwanz da Silva

Universidade Federal do Paraná, Brasil

http://lattes.cnpq.br/3519499649641325

fabricio@unemat.br

André Ximenes de Melo

Universidade do Estado de Mato Grosso, Brasil

http://lattes.cnpq.br/3034808713550502

msc.andreximenes@gmail.com

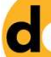

DOI: 10.6008/SPC2179-6858.2017.001.0006
Received: 18/04/2016

Approved: 20/05/2016

\section{Referencing this:}

MELO, S. A. B. X.; SILVA, F. S.; MELO, A. X.. Aspectos socioeconômico dos agricultores familiares extrativistas do cumbaru no município de Poconé - Pantanal Mato-Grossense. Revista Ibero-Americana de Ciências Ambientais, v.8, n.1, p.62-73, 2017. DOI: http://doi.org/10.6008/SPC2179-6858.2017.001.006 


\section{INTRODUÇÃO}

A agricultura familiar, no Brasil, é o resultado de um processo histórico iniciado com a colonização, no século XVI, e vem sendo influenciada pelos eventos políticos, econômicos e sociais. Foi definida a partir de três características centrais: a) a gestão da unidade produtiva e os investimentos realizados por indivíduos que mantém entre si laços familiares; b) a maior parte do trabalho é igualmente fornecida pelos membros da família; e, c) a propriedade dos meios de produção pertence à família, nesta realiza-se a transmissão em caso de retirada ou falecimento de um ou mais dos responsáveis pela unidade produtiva (FAO/ INCRA, 1996; SILVA; JESUS, 2010).

No entanto, com a diminuição das atividades agrícolas, na geração do emprego e na composição da renda das pessoas e famílias residentes no meio rural houve uma mudança estrutural nas unidades, em que parte dos membros das famílias passa a dedicar-se às atividades não agrícolas, praticadas dentro e fora das propriedades rurais, nomeadas de pluriatividade (LOPES, 2009).

A pluriatividade é um o fenômeno pelo qual membros das famílias que habitam o campo e atuam em diversas atividades com o objetivo de obter uma remuneração pelas mesmas, e tanto pode se desenvolver no interior como no exterior da própria exploração, através da força de trabalho familiar, da prestação de serviços a outros agricultores ou de iniciativas centradas na própria exploração, mantendo a moradia na zona rural e uma ligação, inclusive, produtiva, com a agricultura e a vida no espaço rural, e conjuntamente impliquem no aproveitamento de todas as potencialidades existentes na propriedade e/ou em seu entorno (SCHNEIDER, 2003; MARAFON, 2006).

No Brasil, essa prática vem se fortalecendo gradativamente, impulsionada pelas necessidades das famílias de agricultores buscarem alternativas para sustento de suas famílias diante das dificuldades, apenas com o trabalho realizado em suas propriedades. Em consequência, a pluriatividade passou a ter um papel importante para a agricultura familiar pela oportunidade de novas alternativas de aumento da renda. $\mathrm{O}$ que contribui com o desenvolvimento econômico do País na geração de riqueza e empregos para os agricultores, além de exercer um papel social fundamental na mitigação do êxodo rural e da desigualdade social do campo e das cidades, e tem se expandido por todas as regiões em número cada vez mais crescentes, como é o caso do estado de Mato Grosso, que adota o modelo de agricultura familiar com emprego de sistemas diversificados (SILVA; JESUS, 2010; SILVA, 2013).

Alguns trabalhos exercidos de forma complementar, como o extrativismo, elevam a renda da família, promovem a geração de empregos, reduzem o êxodo rural, estimulam o desenvolvimento local e, consequentemente, propiciam o desenvolvimento rural, sustentabilidade ambiental e apresentam papel relevante para o desenvolvimento do Estado (SCHNEIDER, 2003; NAVARRO, 2010).

Nesse modelo, a agregação de valor acontece por um conjunto de atividades desenvolvidas para planejar, produzir, comercializar, distribuir e manter determinado tipo de produto ou serviço, realizando todo esse processo de forma eficaz e eficiente, com baixo custo ou da melhor forma para que os concorrentes gerem vantagem competitiva sobre os mesmos (PORTER, 1989). 
As atividades não agrícolas desenvolvidas paralelamente, como é o caso do extrativismo vegetal, pode ser considerado como um exemplo de atividade heterogênea e de desenvolvimento sustentável, pois considera os recursos naturais e ambientais como recursos produtivos, cuja conservação está fortemente vinculada ao bem-estar social e econômico da população regional.

Segundo Rêgo (1997) o extrativismo vegetal não é somente uma coleta, se insere num conjunto de relações econômicas, sociais e culturais que as unidades familiares estabelecem com o mercado, a sociedade e a natureza. Da mesma forma, o caráter familiar da produção a insere num conjunto de relações, na qual a lógica da produção e a reprodução familiar, maximizando a produtividade do trabalho e reproduzindo suas formas peculiares, sinérgicas, de relações com a natureza, sejam aliadas e não inimigas a serem destruídas.

Para esses extrativistas as relações sociais, especialmente, as relações de confiança, cooperação e reciprocidade consolidam os laços e a permanência dos membros no campo (TOMAS et al., 2012). Os autores argumentam que existe todo um simbolismo que reforça valores humanos além dos valores econômicos envolvidos. A reciprocidade baseia-se no ato de dar, de forma generosa e gratuita, de receber e de retribuir, formando um processo de solidariedade, ajuda mútua, fortalecendo a confiança, pois o ato de dar é mais que uma mera troca.

O extrativismo vegetal não madeireiro do cumbaru (Dipteryx alata Vogel), comum nas unidades familiares de áreas do Cerrado e do Pantanal, é mais uma fonte de renda para os pequenos agricultores que vivem nesses biomas e ajudam a preservar a vegetação nativa, ao evitar a derrubada das árvores e risco de extinção.

Nesse sentido, Arakaki (2009) argumenta que seria ideal nos assentamentos rurais o uso da espécie nativa Dipteryx alata na implantação de sistemas agroflorestais (SAF's) que podem promover a integração de áreas, considerando a participação dos atores extrativistas. Os SAF's podem ocorrer com a combinação de bananeiras, café e uma espécie produtora de madeira como o cumbaru, pode ser caracterizado como um consórcio agroflorestal, bem como silvipastoril com a inclusão de uma gramínea nativa ou exótica. Ou seja, uma agricultura familiar que conservasse o solo mantendo a matéria orgânica, promovendo desenvolvimento vegetal e animal, aumentando, assim, o lucro do proprietário.

O cumbaru também é utilizado na reposição florestal, importante fonte de alimentos para a fauna, a espécie atrai aves e mamíferos que dispersam as sementes e trazem sementes de outras espécies, enriquecendo a diversidade local. Dessa forma, verifica-se a importância ecológica, econômica e social da Dipteryx alata Vogel na manutenção dos fragmentos florestais.

A exploração do fruto do cumbaru é apontada como estratégica para a conservação sustentável da biodiversidade, um apelo à manutenção da floresta nativa. Outros produtos como pequi, castanha-do-Brasil, buriti, babaçu, açaí, andiroba, copaíba, entre outros, impulsionam a economia e fazem parte do extrativismo brasileiro e da conservação da biodiversidade (ARAKAKI et al., 2009; BASSINI, 2008; SANO et al., 2004).

$\mathrm{Na}$ tentativa de minimizar os efeitos do avanço da agricultura comercial sobre os remanescentes da vegetação, alguns órgãos públicos tomam iniciativas que vão desde a criação de unidades de conservação até ações direcionadas à valorização dos produtos provenientes da exploração sustentável nesses biomas. 
Apesar de se constituírem iniciativas ainda bastante tímidas, as ações voltadas para o fortalecimento de produtos e serviços gerados, a partir dos componentes da biodiversidade, têm constado de projetos geridos por órgãos setoriais em nível federal e estadual e também por organizações não governamentais. Como resultado desses esforços, pequenas quantidades desses produtos começaram a ser consumidas nos centros urbanos, como é o caso da amêndoa do cumbaru e as diversas polpas de frutos e castanhas (MAGALHÃES, 2011).

No município matogrossense de Poconé a atividade de extrativismo não madeireiro do cumbaru é desenvolvida por populações dos assentamentos da reforma agrária, comunidades tradicionais, produtores rurais, descendentes indígenas e comunidades Quilombolas, que aproveitam os frutos na alimentação, quanto as propriedades nutricionais e medicinais. A atividade é importante para esses povos em dois aspectos: primeiro, o econômico, como fonte de geração de renda às famílias, contribuindo para o poder de compra, devido à renda adquirida com a venda dos produtos extrativistas, e o segundo, o aspecto social, por envolver a população contribuindo assim para a consolidação das formas tradicionais de vida social, econômica e alimentar das comunidades envolvidas (MENDES, et al.,2014; REGO, 1997).

De acordo com Vieira et al. (2006) um dos grandes problemas das comunidades tradicionais do Centro-Oeste, é a ausência de segurança alimentar, reforçada pela falta de mecanismos que promovam a geração de renda. Os recursos naturais possuem papel importante aos membros da comunidade pela diversidade de usos, manifestada na quantidade de espécies potencialmente econômicas.

Ressalta-se, portanto, que conhecer a realidade e as necessidades dos agricultores das comunidades rurais oportuniza buscar alternativas de melhorias, possibilitando a permanência dos agricultores familiares nas atividades rurais e o fortalecimento da agricultura familiar, assim como desenvolver ação estratégica para fomentar procedimentos que viabilizem o desenvolvimento local.

Diante do exposto, o objetivo desse estudo foi traçar o perfil socioeconômico dos agricultores familiares que desenvolvem atividade extrativista do fruto do cumbaru (Dipteryx alata Vogel) no município de Poconé, Pantanal Mato-grossense.

\section{METODOLOGIA}

A pesquisa, realizada no primeiro semestre de 2014, foi do tipo exploratória e descritiva, teve abordagem qualitativa, com dados primários levantados pelos pesquisadores por meio de entrevista, realizada com uso de formulários e roteiros semiestruturados, contendo 160 questões de múltipla escolha e complementar dissertativa para 22 famílias (com um membro auto identificado como o responsável pelo grupo familiar), tendo sido também efetuada observação em visita às comunidades.

A população-alvo do estudo foi composta por agricultores familiares que desenvolvem atividade extrativista e instituições que participam da cadeia do cumbaru. Os agricultores foram selecionados pelo método de amostragem snowball (bola de neve), com base em dados fornecidos inicialmente pelas entidades que processam a castanha de cumbaru. 
A coleta de dados ocorreu em Poconé, no município brasileiro do estado de Mato Grosso, em ambiente de Pantanal (Figura 1). O Município situa-se a $100 \mathrm{~km}$ da capital do estado, Cuiabá. Sua área territorial é de $2.454,108 \mathrm{~km}^{2}$, possui 31.778 habitantes, destes 23.062 da zona urbana e 8.716 da zona rural (IBGE, 2015).

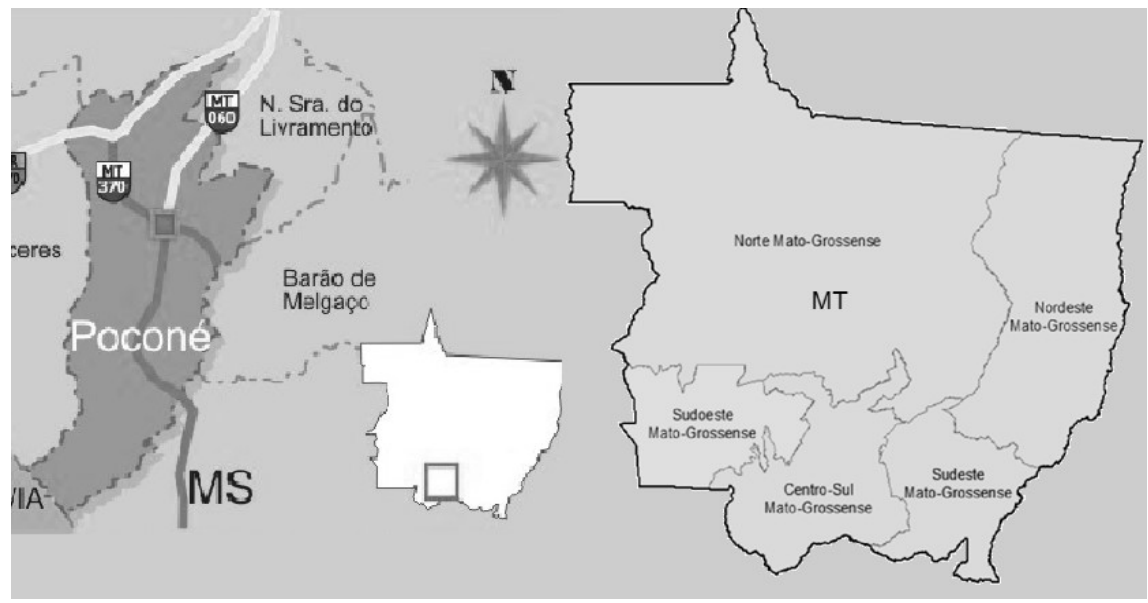

Figura 1: Localização do município estudado, no Pantanal em Mato Grosso. Fonte: SEPLAN (2014).

O município apresenta IDH de 0,652, considerado médio, entretanto, ocupa a $118^{a}$ posição em relação aos 141 municípios do estado de Mato Grosso e em nível nacional, Poconé está na 3020a posição em relação aos 5.565 municípios do Brasil (PNUD, 2013).

Dentre as atividades econômicas desenvolvidas no município de Poconé, destacam-se: a pecuária extensiva (praticada na região pantaneira), o turismo ecológico, o extrativismo mineral e vegetal e a agricultura de subsistência (SEPLAN, 2014).

Para averiguar e acompanhar os padrões éticos e morais da investigação, a pesquisa foi submetida ao Comitê de Ética em Pesquisa (CEP) da Universidade do Estado de Mato Grosso (UNEMAT), obtendo aprovação (Parecer CEP número 23679314.9.0000.5166/2014). Os agricultores que aceitaram participar da pesquisa assinaram o termo de consentimento livre e esclarecido (TCLE), com informação sobre o conteúdo da pesquisa, e autorizaram a divulgação dos dados fornecidos por eles.

\section{RESULTADOS E DISCUSSÃO}

O agente extrativista, no âmbito desta pesquisa, é representado por agricultores familiares pertencentes as comunidades tradicionais, por serem descendentes de índios e/ou quilombolas. Caracterizam-se pelo modo de vida básico da agricultura familiar, ou seja, produzem para o autoconsumo e comercializam o excedente para suprir as necessidades dos membros familiares.

A atividade extrativista é realizada predominantemente por mulheres, o que corrobora à ideia preconizada por Oakley (2004), que em diversas culturas a mulher é a principal responsável pelo cultivo e exploração das espécies vegetais no ambiente familiar (MENDES et al, 2014).

Um dos temas recorrentes nos estudos sobre mulheres extrativistas é a sua atuação no uso dos recursos naturais, particularmente, as práticas consideradas fundamentais à conservação da biodiversidade. 
A mulher, de maneira geral e, em específico aquela que reside no meio rural, assume o perfil de responsável pela promoção da subsistência familiar e do desenvolvimento organizado de suas comunidades. Isso ocorre porque elas encontram-se diretamente ligadas à natureza pelo trabalho ser baseado na estabilidade, diversidade e busca de sustento familiar, sem excedentes, fazem uso equilibrado dos recursos e viabilizam medidas favoráveis ao ambiente (SOUZA, 2012).

A faixa etária predominante entre os agricultores está entre 31 e 50 anos (Tabela 1). Cada família possui de dois a três filhos, com idades que variam de 1 a 20 anos. Segundo Souza (2012) a participação dos mais jovens, além de revitalizar o sistema de produção com novas ideias, permite a continuidade das técnicas utilizadas, porém, modernizadas e competitivas conforme a exigência do mercado, favorecendo a sucessão familiar no campo.

Tabela 1: Idade dos agricultores entrevistados.

\begin{tabular}{lcc}
\hline Idade & Frequência absoluta & Frequência relativa (\%) \\
\hline 20 a 30 anos & 1 & 4,55 \\
\hline 31 a 40 anos & 9 & 40,91 \\
\hline 41 a 50 anos & 8 & 36,36 \\
\hline Acima de 50 anos & 4 & 18,18 \\
\hline Total & 22 & 100 \\
\hline
\end{tabular}

Grande parte dos agricultores estão em idade considerada produtiva, repercutindo na mão de obra do extrativismo do cumbaru, pois a atividade necessita de grande esforço físico devido o fruto ser coletado no chão, fazendo com que os extrativistas fiquem horas encurvado, esse esforço de agachamento para a coleta do fruto e depois para o transporte por longas distâncias até o armazenamento é dificultado para os extrativistas mais idosos.

Existem preocupações respeito do processo de envelhecimento da população em decorrência do êxodo rural. Godoy et al. (2010) afirmam que no meio rural é possível visualizar dois fenômenos: o envelhecimento da população e o êxodo de jovens rurais para os centros urbanos. Fatores que trazem consigo o problema da reprodução social da família rural, os jovens migram para os centros urbanos por falta de renda atrativa. Não obstante, nos centros urbanos ocorrem graves problemas sociais decorrentes do mesmo, como: o inchaço das cidades, surgimento de inúmeras favelas, falta de saneamento, saúde, escola e transporte.

Quanto à escolaridade, o percentual de agricultores que cursou até o ensino médio foi de $14 \%$, a maioria (55\%) concluiu o ensino fundamental e $31 \%$ não concluiu o ensino fundamental. Se comparado com a média do Brasil, de acordo com o Senso IBGE (2010) o percentual de pessoas com 18 anos ou mais de idade nas áreas rurais em 2010 concluído o ensino médio era de16,35\%, o ensino fundamental 16,35\% e sem qualquer tipo de escolaridade era de $25 \%$. A participação desse grupo que possuía nível superior (completo ou incompleto), era quase que inexpressiva (apenas $3 \%$ ).

Esse resultado reflete na dificuldade de expansão dos mercados e na falta de informações de novas tecnologias essenciais para o desenvolvimento dessa atividade. Portanto, são necessários programas de 
educação de adultos, com o objetivo de capacitar os agricultores para enfrentar os crescentes desafios da sociedade. Ressalta-se que os filhos em idade escolar estão matriculados em escolas da região.

Os agricultores familiares extrativistas residem em propriedades rurais, sendo que as atividades agrícolas da comunidade estão voltadas, em sua maioria, para as culturas de subsistência, que representam o sustento da família. A cultura mais expressiva é da mandioca, produzida por $36 \%$ dos agricultores familiares, seguido da produção de espécies frutíferas (banana, melancia, pequi, etc.), conforme Tabela 2.

Tabela 2: Culturas de consumo para subsistência presentes nas propriedades dos agricultores pesquisados.

\begin{tabular}{lc}
\hline Culturas de consumo & Frequência \\
\hline Mandioca & 36 \\
\hline Fruteiras (banana, Melancia, pequi...) & 27 \\
\hline Milho & 23 \\
\hline Abobora & 23 \\
\hline Horta & 14 \\
\hline Batata-doce & 9 \\
\hline Pasto + cana & 9 \\
\hline Arroz & 5 \\
\hline Feijão & 5 \\
\hline Outros & 5 \\
\hline
\end{tabular}

Mendes et al. (2014) também verificaram em pesquisa do perfil dos agricultores familiares extrativistas da região sudoeste mato-grossense, que $93 \%$ das famílias agricultoras praticam mais de um sistema de produção nas unidades produtivas.

Relativo às atividades econômicas é apresentada as principais atividades que compõem a renda monetária das famílias pesquisadas. Constata-se que a agricultura contribui com $41 \%$ das atividades, os agricultores plantam para comercializar milho, mandioca, abobora, batata doce, banana, pequi, entre outras. Ainda $27 \%$ cultivam horta, outras atividades ajudam na complementação da renda, como: doces e conservas (Tabela 3). Outras $27 \%$ das famílias prestam serviços diversos, tais como: capina, desmatamento, manejo de animais, reparação de cerca em áreas rurais, entre outros; e são remunerados, em média, com o valor de R\$ 30,00 por dia. Situação que segundo Guanziroli et al. (2001) que ocorre com a maioria das pessoas na agricultura familiar, que dependem de rendas complementares, como aposentadorias, vendas de serviços em outros estabelecimentos ou atuando em atividades não agrícolas.

Tabela 3: Três principais fontes de renda dos agricultores entrevistados em ordem crescentes de importância.

\begin{tabular}{lcc}
\hline Fontes de Renda & Frequência absoluta & Frequência relativa (\%) \\
\hline Agroindústria, horta e produtos florestais não madeireiro & 1 & 4,55 \\
\hline Aposentadoria, frango e produção doces & 1 & 4,55 \\
\hline Agricultura, pecuária e PFNM & 1 & 4,55 \\
\hline Prestação de serviços, PFNM e bolsa família & 1 & 4,55 \\
\hline Agricultura e PFNM & 1 & 4,55 \\
\hline Horta e PFNM & 1 & 4,55 \\
\hline Prestação de serviços & 1 & 4,55 \\
\hline Prestação de serviços e horta & 2 & 9,09 \\
\hline Aposentadoria e PFNM & 2 & 9,09 \\
\hline Agricultura, horta e PFNM & 2 & 9,09 \\
\hline Prestação de serviços e PFNM & 4 & 18,18 \\
\hline Agricultura, PFNM e prestação de serviços & 5 & 22,73 \\
\hline Total & 22 & 100 \\
\hline
\end{tabular}


A exploração de amêndoa do cumbaru (Produtos Florestais Não Madeireiros - PFNMs) está presente entre as três principais fontes de renda das famílias pesquisadas (81,82\%). O que mostra a importância do extrativismo na formação financeira dos agricultores como atividade não-agrícola.

No que se refere à importância das atividades não-agrícolas de exploração de produtos florestais não madeireiros nos rendimentos domésticos monetários e não monetários, os recursos oriundos da comercialização da amêndoa do cumbaru complementam a renda para $77,2 \%$, o que contribui com menos de $20 \%$ no pagamento das despesas anuais da família, porém, eles afirmam ser vantajosa a exploração do cumbaru, pois podem conciliar com trabalho fora da propriedade, diversificam a produção, além de apresentar menor trabalho que na atividade de lavoura (Tabela 4).

Tabela 4: Contribuição da amêndoa de cumbaru na renda anual familiar dos agricultores, por faixa de despesa.

\begin{tabular}{lc}
\hline Faixa de despesa & Frequência relativa (\%) \\
\hline Cobre acima de 70\% das despesas da família & 14 \\
\hline Cobre entre 69\% e 40\% das despesas da família & 5 \\
\hline Cobre entre 39\% e20\% das despesas da família & 5 \\
\hline Cobre entre 19\% e 1\% das despesas da família & 77 \\
\hline Total & 100 \\
\hline
\end{tabular}

Resultado semelhante foi obtido na pesquisa de Magalhães (2011), sobre o extrativismo do baru em três municípios de Goiás, em que foi constatado que $52 \%$ dos recursos oriundos da extração e comercialização da amêndoa cobrem apenas $20 \%$ das despesas. Esse é um aspecto positivo para a questão ambiental, significa que a atividade de extrativismo contribui somente para complementação financeira, não ocorrendo ameaça de esgotamento de recursos pela exploração em excesso. Rego (1997) argumenta que a exploração de recursos vegetais com diversificação dos recursos em sistemas de coleta, cultivo e criação de animais ou produção de outras atividades, estão fundadas em culturas tradicionais, favorecendo a relação harmônica com a natureza.

Desse modo, a atividade do extrativismo sustentável pode obter maior relevância econômica se houver uma forma de agregar valor, desenvolvendo produtos do fruto do cumbaru para auxiliar financeiramente as famílias tais como: adubo, farinha da polpa, artesanato, carvão, amênda para acompanhamento de peritivos, produção de manteiga, óleo refinado, farelo, produtos de higiêne e beleza, bem como uso medicinal (CARRAZZA, 2010).

A comercialização da amêndoa acontece por meio de associações e cooperativa do municipio. As 22 famílias pesquisadas obtiveram na safra de 2013 (entre agosto e outubro) renda média de R\$ 920,00 por familia, conforme demonstrado na Tabela 5.

Tabela 5: Faturamento com a comercialização da amêndoa de cumbaru por famíilia extrativista pesquisada, na safra de 2013.

\begin{tabular}{lcc}
\hline Valor obtidos por família (em Reais) & Frequência absoluta & Frequência relativa (\%) \\
\hline De 0 a 600 & 10 & 45 \\
\hline de 601 a 1000 & 7 & 32 \\
\hline de 1001 a 1600 & 2 & 9 \\
\hline de 1601 a 2000 & 0 & - \\
\hline de 2001 a 2600 & 1 & 5 \\
\hline de 2601 a 3000 & 0 & -
\end{tabular}


Maior que 3000

Total

2

22

\section{9}

100

Metade dos entrevistados afirmaram que os rendimentos provenientes da exploração de uma safra do cumbaru possibilitam o atendimento às necessidades básicas da sua família, como a aquisição de vestuário e alimentação. Sendo que algumas famílias aproveitam a safra para adquirir eletrodomésticos que facilitam as atividades domésticas. Assim, os benefícios sociais gerados com o extrativismo influenciam na qualidade de vida das famílias.

Entretanto, a atividade apresenta desafios que devem ser superados à medida que sejam desenvolvidos projetos de agregação de valor às matérias-primas e adotadas medidas de inserção no mercado. Há necessidade de políticas voltadas para o favorecimento do manejo comunitário sustentável de PFNMs, tais como: ser específicas da atividade de exploração de PFNMs; considerar a cultura e a realidade da comunidade e atender à peculiaridade da região.

Quanto as características técnicas dos extrativistas, verificou-se que a maioria deles não faz o planejamento das atividades e não conhece a realidade do mercado que pretendem se inserir, ou que estão inseridos. Nessa ótica, o extensionismo é importante nessas unidades, na transformação tanto no campo social quanto na tecnologia, contribuindo para o desenvolvimento rural, possibilitando o aumento de renda da família e a melhoria das condições de vida desta população.

Dos agricultores $72,8 \%$ são proprietários da terra e $27,2 \%$ não o são, esses residem e/ou trabalham em propriedades de terceiros. A área de $22,7 \%$ das propriedades nas unidades de produção apresenta entre 01 e 10 hectares, não foi encontrada no âmbito da pesquisa, nenhuma unidade de produção que ultrapassasse 65 hectares (Tabela 6). Esta característica faz com que as atividades e comportamentos sejam diferentes entre os agricultores.

Tabela 6: Tamanho das unidades agrícolas familiares.

\begin{tabular}{lcc}
\hline Tamanho (ha) & Frequência absoluta & Frequência relativa (\%) \\
\hline Não possui área & 6 & 27,27 \\
\hline 0,1 a 10 ha & 5 & 22,72 \\
\hline 10,01 a 20 ha & 3 & 13,64 \\
\hline 20,01 a 30 ha & 2 & 9,09 \\
\hline 30,01 a 40 ha & 5 & 22,73 \\
\hline$<50$ há & 1 & 4,55 \\
\hline Total & 22 & 100 \\
\hline
\end{tabular}

Foi verificado que $95,5 \%$ da mão de obra utilizada nas unidades agrícolas é familiar. Essa característica é esperada, pois o uso da mão-de-obra familiar é um traço fundamental na organização familiar de produção. Em apenas 4,5\% das unidades foi citada mão de obra externa, esta força de trabalho é empregada apenas temporariamente, quando as unidades agrícolas se apresentam mais intensificadas.

Em relação a infraestrutura de armazenagem e logística da economia dos agricultores, verificou-se a inexistência de galpões comunitários para armazenar os frutos coletados, dessa forma até o final da safra, 91\% dos frutos são armazenados na residência do agricultor e 9\% em paiol coletivo, onde é distribuído para processamento. 
O meio de transporte dos frutos, do local da coleta até o armazenamento (antes da extração) é feito com uso de bicicleta por $36 \%$ das famílias, $27 \%$ transportam a pé, $23 \%$ utilizam veículo automotor e $14 \%$ recorrem a motocicleta, assim o transporte depende das condições financeiras do agricultor e da distância percorrida.

Embora a exploração do cumbaru apresente potencialidade de alavancagem e desenvolvimento da economia do município, as dificuldades de infraestrutura e logística, principalmente, no transporte, oneram os custos do produto que recai sobre o consumidor.

No que diz respeito às ações coletivas, constatou-se a existência de normas de confiança, colaboração, solidariedade, cooperação, reciprocidade e organização coletiva entre os membros da comunidade, o que Ihes permite negociação em conjunto. Os agricultores possuem boa relação com a vizinhança, geralmente visitam-se e participam de atividades festivas culturais da região, como: Mascarados - dança tradicional e folclórica de Poconé, festa de São Benedito. Entretanto, verificou-se que os agricultores pesquisados não têm o hábito de se reunir para preparação dos produtos, há pouca participação em reuniões de associações, cooperativas e não contam com serviços de assistência técnica e extensão rural.

\section{CONCLUSÕES}

A presença da pluriatividade, combinando as atividades agrícolas e não agrícolas nas unidades familiares está explicita nos agricultores familiares que desenvolvem atividade extrativista do fruto do cumbaru, (Dipteryx alata Vogel) no município de Poconé, MT. A atividade extrativista promove o crescimento econômico, social e ambiental, permite que as famílias melhorem as condições de vida, possibilitando que os agricultores permaneçam na terra.

A atividade contribuiu para o desenvolvimento local, além de colaborar para conservação da vegetação do bioma Pantanal, mais especificamente a unidade de Poconé. Apesar das dificuldades enfrentadas, os agricultores acreditam que a atividade é viável e necessitam de treinamento e assistência técnica para melhor desenvolvê-la.

Ressalta-se a necessidade de implantação de políticas públicas voltadas para o campo, como tecnologia, treinamento, assistência técnica que possibilitem o desenvolvimento das atividades extrativistas, assim como, a logística, distribuição do produto acabado, para que as demais famílias sejam inseridas na atividade extrativista e que as famílias inseridas possam aumentar sua renda.

\section{AGRADECIMENTOS}

À Fundação de Amparo à Pesquisa do Estado de Mato Grosso - FAPEMAT, pela concessão da bolsa de estudos com apoio da CAPES.

\section{REFERÊNCIAS}

ARAKAKI, A. H.; SCHEIDT, G. N.; PORTELLA, E. J. A.; COSTA, R. B.. O baru (Dipteryx alata Vog.) como alternativa de sustentabilidade em área de fragmento florestal do Cerrado, no Mato Grosso do Sul. Interações, Campo Grande, v.10, n.1, p.31-39, 2009. 
BASSINI, F.. Caracterização de populações de barueiros (Dipteryx alata Vog. \pm Fabaceae) em ambientes naturais e explorados. Tese (Doutorado em Ciências Ambientais) Universidade Federal de Goiás, Goiânia, 2008.

BUAINAIN, A. M. DI SABBATO, A; GUANZIROLI, C. A.. Agricultura familiar: um estudo de focalização regional. In: CONGRESSO DA SOCIEDADE BRASILEIRA DE ECONOMIA E SOCIOLOGIA RURAL, 42. Anais. Cuiabá: SOBER, 2004.

BRASIL. Decreto № 1.946, de 28 de Junho de 1996. Brasília: DOU, 1996.

CARRAZZA, L.; ÁVILA, J.. Manual Tecnológico de Aproveitamento Integral do Fruto do Baru. 2 ed. Brasília: Instituto Sociedade, População e Natureza, 2010.

COELHO, M.. Melhoria na extração de amêndoas de baru (Dipteryx alata) através de equipamento mecânico e sua avaliação. In: ENCONTRO DE JOVENS TALENTOS DA EMBRAPA CERRADOS, 4. Anais. Planaltina: 2009.

FAO/INCRA. Perfil da agricultura familiar no Brasil: dossiê estatístico. Projeto UTF/BRA/036/BRA. 1996.

FERNANDES, I. M.; SIGNOR, C. A.; PENHA, J.. Biodiversidade no Pantanal de Poconé. Cuiabá: Centro de Pesquisa do Pantanal, 2010.

FUNK F.; BORGES, M. A. M.; SALAMONI, G.. Pluriatividade: uma estratégia de sustentabilidade na agricultura familiar nas localidades de Capão Seco e Barra Falsa 3o Distrito - Rio Grande-RS. Geografia, v.15, n.2, 2006.

GLIESSMAN, S. R.. Agroecologia: processos ecológicos em agricultura sustentável. Porto Alegre: EdUFRGS, 2005.

GODOY, C. M. T.; PÉREZ, F. I. C.; WIZNIEWSKY, J. G.; GUEDES, A. C.; MORAES, C. S.. Juventude rural, envelhecimento e o papel da aposentadoria no meio rural: A realidade do município de Santa Rosa/RS. In: CONGRESSO SOBER: SOCIEDADE BRASILEIRA DE ECONOMIA, ADMINISTRAÇÃO E SOCIOLOGIA RURAL, 48. Anais. Campo Grande: 2010.

GODOY, C. M. T.; WIZNIEWSKY, J. G.. O papel da pluriatividade no fortalecimento da agricultura familiar do município de Santa Rosa/RS. Desafio Online, Campo Grande, v.1, n.3, 2013.

GUANZIROLI, C.; ROMEIRO, A.; BUAINAIN, A. M.; DI SABBATO, A.; BITTENCOURT, G.. Agricultura familiar e reforma agrária no século XXI. Rio de Janeiro: Garamond, 2001.

GUIMARÃES, R. C. A.; VIANNA, A. C. A.; MACHADO, A .A.; FAVARO, S. P.. Caracterização química da farinha desengordurada e obtenção do concentrado proteico de amêndoas de baru (Dipteryx alata Vog.). In: SIMPÓSIO NACIONAL SOBRE O CERRADO, 9. Anais. Brasília: 2008.

HOMMA, A. K. O.. História da agricultura na Amazônia: da era pré-colombiana ao terceiro milênio. Belém: Embrapa Amazônia Oriental, 2000.

IBAMA. Portaria № 37-N, de 3 de abril de 1992. Brasília: DOU, 1992.
IBGE. Indicadores de desenvolvimento sustentável: Brasil 2006. Rio de Janeiro: IBGE, 2006.

IBGE. Censo - Brasil 2010. Rio de Janeiro: IBGE, 2010.

LAMARCHE, H. A.. Agricultura familiar: comparação internacional: uma realidade multiuniforme. Campinas: UNICAMP, 1993.

LOPES, E. S. A.; COSTA, J. E.. Territórios rurais e agricultura familiar no Nordeste. São Cristovão: EdUFS, 2009.

MACIEL, R. C. G; REYDON, B. P.; COSTA, J. A.; SALES, G. O. Pagando pelos serviços ambientais: uma proposta para a reserva extrativista Chico Mendes. Acta Amazonica, v.40, n.3, p.489-498, 2010.

MAGALHÃES, R. M.. Obstáculos à exploração do cumbaru (Dipteyx alata Vog.) no Cerrado Goiano: sustentabilidade comprometida?. Tese (Doutorado em Politica e Gestão Ambiental) - Universidade de Brasília, Brasília, 2011.

MARAFON, G. J.. Agricultura familiar, pluriatividade e turismo rural: reflexões a partir do território fluminense. Campo-Território: Revista de Geografia Agrária, Uberlândia, v.1, n.1, p.17-60, 2006.

MARTINS, B.. Desenvolvimento tecnológico para o aprimoramento do processamento de polpa e amêndoa do baru (Dipteryx alata Vog.). Tese (Doutorado em Tecnologia de Alimentos) - Universidade Estadual de Campinas, Campinas, 2010.

MELO, A. X.; CUNHA, V. P.; MELO, S. A. B. X.; TRELHA, I. M.; OLIVEIRA, F. L. L.. Estratégias da produção de tomate em Mato Grosso. In: CONGRESSO INTERNACIONAL DE ADMINISTRAÇÃO. Anais. Ponta Grossa: 2012.

MELO, S. A. B. X.. Sustentabilidade socioeconômica e ambiental da cadeia produtiva do cumbaru (Dipteryx alata Vogel) em Poconé/MT, Bioma Pantanal. Dissertação (Mestrado em Ambiente e Sistemas de Produção Agrícola) Universidade do Estado de Mato Grosso, Tangará da Serra, 2015.

MENDES, M. F; NEVES, S. M. A.; SILVA; J. S. V; NEVES, R. J; SILVA, T. M.. Perfil dos agricultores familiares extrativistas da região sudoeste matogrossense, pertencente à bacia do Alto Paraguai - Brasil. Bol. geogr., Maringá, v.32, n.3, p.94-109, 2014.

MENDES, M. F; NEVES, S. M. A.; NEVES, R. J; SILVA; SILVA, T. $M$.. A organização das mulheres extrativistas na região Sudoeste mato-grossense, Brasil. Estudos Feministas, Florianópolis, v.22 n.1, p.416, 2014.

NAVARRO, Z.. A agricultura familiar no Brasil: entre a política e as transformações da vida econômica. In: GASQUES, J. G.; VIEIRA FILHO, J. E.; NAVARRO, Z.. A agricultura brasileira: desempenho, desafios e perspectivas. Brasília: IPEA, 2010. p.185-209

NEPOMUCENO, D.. O extrativismo de baru (Dipteryx alata Vog) em Pirenópolis (GO) e sua sustentabilidade.

Dissertação (Mestrado em Ecologia e produção Sustentável) - Universidade Católica de Goiás, Goiânia, 2006. 
NOBREGA, M. J. L.; COSTA, C. C.; BARBOSA, J. W. S; REIS, C. Q.; SILVA, M. P. N. S.. Perfil socioeconômico e ações dos agricultores familiares da comunidade rural de flores em Pombal, PB. INTESA, Pombal, v.8, n.1, p.44-56, 2014.

OAKLEY, E.. Quintais domésticos: uma responsabilidade cultural. Agriculturas, v.1, n.1, p.37-39, 2004.

OYAMADA, G. C.; PEREIRA, B. D.; SILVA, G. R.; MENDES, C. M.; FARI, A. M.. Agricultura familiar e pluriatividade: estudo de caso em comunidade de Mato Grosso. Revista de Estudos Sociais, v.9, n.1, p.29-46, 2007.

PIMENTEL, N.. Processo produtivo para o aproveitamento dos produtos florestais não-madeireiros do baru (Dipteryx alata Vog.). Dissertação (Mestrado em Ciências Florestais) Universidade de Brasília, Brasília, 2008.

PNUD Brasil. Programa das Nações Unidas para o Desenvolvimento. Desenvolvimento Humano e IDH. 2013.

PORTER, M.. Estratégia competitiva: técnicas para análise da indústria e da concorrência. Rio de Janeiro: Campus, 1980.

RÊGO, J. F.. Análise econômica de sistemas básicos de produção familiar rural no vale do Acre. Rio Branco: UFAC, 1996.

SANO, S. M.; RIBEIRO, J. F.. Baru: biologia e uso. Planaltina: Embrapa Cerrados, 2004.

SEPLAN. Secretaria de Estado de Planejamento e Coordenação Geral. Anuário Estatístico 2004. Cuiabá: SEPLAN, 2004.

SCHNEIDER, S.. Teoria social, agricultura familiar e pluriatividade. RBCS, v.18, n.51, 2003.
SCHNEIDER, S.. S. As novas formas de trabalho no meio rural: a pluriatividade e as atividades rurais não-agrícolas. Revista Redes, Santa Cruz do Sul, v.9, n.3, p.75-109, 2005.

SILVA, J. R.; JESUS, P.. Juventude rural e agricultura familiar: os determinantes dos processos migratórios e desafios para a preservação da agricultura familiar. In: CONGRESSO LATINOAMERICANO DE SOCIOLOGIA RURAL, 8. Anais. Porto de Galinhas, 2010.

SILVA, R. N.. Pluriatividade na agricultura familiar tradicional do estado de Mato Grosso. Dissertação (Mestrado em Desenvolvimento Local) - Universidade Católica Dom Bosco, Campo Grande, 2013.

SOUZA, F. M.. Caracterização socioeconômica e ambiental de produtos florestais não madeireiros de familias agroextrativistas em Quatro Municipios de Goiás. Dissertação (Mestado em Ciências Florestais) - Universidade de Brasilia, Brasilia, 2012.

TAKEMOTO, E.; OKADA, I. A.; GARBELOTTI, M. L.; TAVARES, M.; PIMENTEL, S. A.. Composição química da semente e do óleo de baru (Dipteryx alata Vog.) nativo do Município de Pirenópolis, Estado de Goiás. Rev. Inst. Adolfo Lutz, v.60, n.2, p.113-117, 2001.

TOMAS, R. N.; SPROESSER, R. L.; BATALHA; M. O.. Convenções, capital social e desenvolvimento efetivo na agricultura familiar: o caso de mato grosso do sul. Organizações Rurais \& Agroindustriais, Lavras, v.14, n.3, p.409-425, 2012.

WHA. World Health Association. Division of Mental Health. Qualitative Research for Health Programmes. Geneva: WHA, 1994. 